\title{
The Addition of Chitosan to GnRH Analog Induces Ovarian Resumption and Improves Conception Rates in Buffaloes
}

\author{
Y. A. Amin ${ }^{\mathrm{a}, *}$ \& A. Said ${ }^{\mathrm{b}}$ \\ a'Department of Theriogenology, Faculty of Veterinary Medicine, Aswan University, Aswan, Egypt \\ ${ }^{b}$ Electronic and Nano Devices Lab, Faculty of Science, South Valley University, Qena, Egypt \\ ${ }^{*}$ Corresponding author: yahiaamin2030@gmail.com \\ (Received 31-05-2020; Revised 21-07-2020; Accepted 13-08-2020)
}

\begin{abstract}
During hot season, female buffaloes suffer from ovarian inactivity due to hormonal insufficiency. Therefore, impaired reproductive efficiency causes low productivity of female buffaloes. The present study aimed to compare the effect of chitosan and/or insulin addition to GnRH analog during modified Ovsync program on ovarian response and pregnancy establishment in postpartum anestrous buffaloes during low breeding during the summer season. This study was carried out in buffaloes $(\mathrm{N}=135)$ suffering from ovarian inactivity during the summer season. The animals were divided into three treated equal groups, i.e., Group (1) basic Ovsync protocol, Group (2) insulin-sync protocol, and Group (3) chitosan-sync protocol. Blood samples were analyzed for progesterone, estradiol, and insulin concentrations before and after treatment. Follicular dynamics were studied through transrectal scanning of the ovaries. The results revealed that administration of insulin to GnRH analog (G2) significantly increased the diameter of the largest follicle and improved the conception rate compared to basic Ovsync protocol (G1). The addition of chitosan to GnRH analog (G3) caused a significant increase in the estrous induction rates $(86.6 \%)$, increased the size of the largest follicle $(\mathrm{p}<0.05)$, and improved conception rates $(76.9 \%)$ compared to basic Ovsync protocol (G1). Serum progesterone concentrations increased after treatment $(p<0.05)$ in all groups indicating the resumption of ovarian activity. In addition, serum estradiol concentration increased after treatment in G2 and G3 $(\mathrm{p}<0.05)$ compared to G1. Therefore, we conclude that the addition of chitosan to GnRH analog induces ovarian resumption and improves conception rates. Subsequently, chitosan-sync protocol can be used in the treatment of the great infertility problem of postpartum anestrous during summer season in buffaloes. Furthermore, this protocol avoids the repeated injection of the animal as in insulin-sync protocol, so that protect the animal from more injection pains in addition to the decreases cost and duration of treatment.
\end{abstract}

Keywords: chitosan; GnRH analog; postpartum anestrous; summer stressed buffaloes; pregnancy

\section{INTRODUCTION}

It is well recognized that buffaloes are the world's second most important animal. Buffaloes have great importance due to their high production potentials through meat and milk. To obtain the full productivity from buffaloes, female buffaloes should have full reproductive performance throughout the year. During the hot season, reproductive efficiency of female buffaloes is impaired by poor estrous expression, long inter-calving intervals, and reduced ovarian activity which in turn causes low productivity of female buffaloes (Das et al., 2014). About $80 \%$ of non-pregnant buffaloes in India suffer from quiescent ovaries during high temperatures in the hot season, especially from March to August when the day length increases. This low breeding efficiency is caused by the decrease in pulse frequency of luteinizing hormone ( $\mathrm{LH}$ ) which is mainly due to the adverse effect of heat stress. Low level of LH results in pernicious effect on maturation of the follicles and estradiol secretion in buffaloes (De Rensis \& Scaramuzzi, 2003). Furthermore, the effect of heat stress extends to influence the conception rate. The pregnancy rate obviously reduces in lactating dairy cows with temperature humidity index (THI) (used for quantifying heat stress) more than 72-73 in cattle (Schüller et al., 2014) and 75 in buffalo (Dash, 2013). The reduction of pregnancy rate due to heat stress also relates to the decline of the first service pregnancy rate of crossbred cows which is occurred when the THI level is above 72 (Khan et al., 2013). In case of buffaloes, it is reported that the decline of fertility is common in subtropical climates which is characterized by heat stress and THI level reaching 75 (Dash et al., 2015). Several studies indicate that buffaloes with aberrant reproduction during summer exhibit alterations in hormonal secretion due to heat stress. A large number of hormonal regimens have been used with varying degrees of efficacy in synchronization of 
ovulation and conception rate (Ghuman et al., 2012). Hormones such as prolactin (PRL), follicle-stimulating hormone $(\mathrm{FSH})$, luteinizing hormone $(\mathrm{LH})$, progesterone (P4), and estradiol 17- $\beta$ are directly associated with this condition. However, Gonadotropin releasing hormone $(\mathrm{GnRH})$ normally induces estrous in bovine, but treatment by its agonist fails to do so in acyclic buffaloes during summer as the response rate is very low $(30 \%)$ (Azawi et al., 2012).

$\mathrm{GnRH}$ analog has a limited half-life which does not exceed 5-6 hours which represents the major side effect of GnRH analog. Therefore, its usage in treatment of acyclic buffaloes is not efficient as it will vary depending on the size and stage of ovarian follicles at the time of treatment. This problem can be solved by using mechanism of drug delivery systems which increase the bioavailability, solubility, and permeability of many potent drugs (Solano-Umaña et al., 2015). Hormone content such as GnRH packed or attached on biodegradable polymer has been used widely nowadays. The polymer is used as a potential hormone carrier by its capability to improve hormone stability and protected it from rapid degradation during its transportation and controlling of bioactive agent releasing (Rather et al., 2013).

Chitosan (CS) is a cationic polymer of natural origin, biodegradable, biocompatible, and non-toxic to living tissues (Domínguez-Delgado et al., 2014). In addition, it has an antibacterial characteristic. Chitosan facilitates drug delivery across cellular barriers and transiently causes opening of the tight junctions between epithelial cells (Boonthum et al., 2018). Chitosan polymers were shown to be attractive alternatives to liposomes for the delivery of peptides, proteins, antigen oligonucleotides, and genes, since they have the advantages of longer shelf life and generally a higher drug carrying capacity (Martínez-Martínez et al., 2018).

Regarding to reproductive aspects, it is reported that conjugation of hormones to chitosan is believed to increase the surge of gonadotropin levels, which results in a good reproductive output with no toxic effect (Rather et al., 2013). Therefore, in the current study, the addition of chitosan to GnRH agonist is expected to improve its absorption, prevent its rapid degradation, overcome its short half-life, and enhance its therapeutic effect.

Insulin has been noticed to influence $\mathrm{LH}$ release from anterior pituitary and regulate ovarian response to gonadotropins. Insulin has been reported to influence the ovarian follicles as it promotes the differentiation and maturation of these follicles (Ramoun et al., 2012) by increasing its sensitivity to the action of FSH. Suguna et al. (2009) find that steroidogenesis and ovulation rate increase after administration of exogenous insulin in goats. In addition, Gupta et al. (2015) try to detect the effect of insulin so he includes insulin with or in place of $\mathrm{GnRH}$ in anestrous buffaloes to do what is called insulin modified Ovsync program.

Therefore, we hypothesize that treatment of buffaloes suffering from postpartum anestrous during summer season by chitosan-sync protocol will induce ovarian cyclicity in anestrous buffaloes, increase estrous induction rate and conception rate. Therefore, modified
Ovsync protocol with chitosan can be used in treatment of great infertility problems of the summer stressed anestrous buffaloes. The present study was designed to compare the effect of addition of chitosan and/or insulin to $\mathrm{GnRH}$ analog during modified Ovsync program on ovarian response and pregnancy establishment in postpartum anestrous buffaloes during low-breeding summer season.

\section{MATERIAL AND METHODS}

\section{Animals and Management}

All procedures were approved and done according to the guidelines approved by the Ethics Committee of the Faculty of Veterinary Medicine, Aswan University, Egypt which basically conforms to the guide for the care and use of laboratory animals of the National Institutes of Health in the USA (NIH publication No. 86-23, revised 1996).

One hundred thirty-five lactating buffaloes (more than five months post-partum), with the age range of $5-8$ years, body weight range of $450-550 \mathrm{~kg}$, and with a range of body condition score of $3.35 \pm 0.50$ on a scale ( $1=$ thin to $5=$ fat) were included in the present study. The feeding ration of experimental buffaloes meets the requirement for maintenance and milk production. The study was performed at a private farm in Qena Province, Egypt during the period extending from April to October (low breeding season for buffalo in Egypt) when the range of ambient temperature was $35-40{ }^{\circ} \mathrm{C}$.

Selections of experimental buffaloes suffering from ovarian inactivity based on the absence of corpora lutea after two rectal palpations and ultrasound examinations of the ovaries (on days -12 and -3 ) and after detection of low progesterone concentration in the serum in two blood samples taken simultaneously at the time of rectal palpation.

The animals $(\mathrm{N}=135)$ were randomly divided into three groups: (1) group of basic Ovsync protocol (G1, $\mathrm{N}=45)$; (2) group of insulin-sync protocol ( $\mathrm{G} 2, \mathrm{~N}=45)$; and (3) group of chitosan-sync protocol (G3, N=45). Each experimental buffalo in G1 was administered 2 IM injections of GnRH agonist (5 mL Receptal, each 1 $\mathrm{mL}$ contained $0.004 \mathrm{mg}$ Buserelin, Intervet, Holland) on Days 0 and 9 (Day $0=$ day of first GnRH injection) in addition to $500 \mu \mathrm{g} \mathrm{PGF}_{2 \alpha}$ analog (Cloprostenol sodium, $2 \mathrm{~mL}$ Estrumate, each $1 \mathrm{~mL}$ contained 250 ug Cloprostenol sodium, Schering Plough, Animal Health, Berkhamsted, England) on Day 7 (Figure 1). In insulin-sync protocol, experimental buffaloes were administered the same treatment regimen as in the basic Ovsync protocol in addition to injection of insulin at a dose of $0.25 \mathrm{IU} / \mathrm{kg}$ body weight by SC injection (Mixtard $30 \mathrm{HM}$, Nova-Nordisk, Bagsvaerd, Denmark) on days -3, -2 , and -1 (Day $0=$ day of first $\mathrm{GnRH}$ injection) (Figure 1). Animals in the chitosan-sync protocol were administered the same treatment regimen as in the basic Ovsync but differed in addition of chitosan to GnRH analog (Receptal) before injection. Each animal received $5 \mathrm{~mL}$ receptal incorporated with $1 \mathrm{~mL}$ chitosan $(0.02 \mathrm{mg}$ buserelin/10 mg chitosan). Administration of GnRH analog 
conjugated with chitosan was applied on days 0 and 9, while injection of $\mathrm{PGF}_{2 \alpha}$ analog was on day 7 as in basic Ovsync protocol (Figure 1).

\section{Preparation of Chitosan}

The preparation of chitosan was carried using the gelation methods (Boonthum et al., 2018). One gram of Chitosan (9012-76-4, Sigma-Aldrich) was dissolved in 50 $\mathrm{mL}$ of distilled water with a high-speed stirrer. During stirring, $50 \mathrm{~mL}$ of $2 \%$ acetic acid was added continuously. After $30 \mathrm{~min}$ of stirring, the aging of the solution was completed. Chitosan incorporated into buserelin with added $2 \mathrm{~mL}$ of chitosan solution, under stirring for $20 \mathrm{~min}$, to $10 \mathrm{~mL}$ of Receptal (Intervet, Holland) vial at room temperature.

\section{Evaluation of Entrapment Efficiency of Chitosan of GnRH Hormone}

Entrapment efficiency (EE) process was determined by separating chitosan from the suspension consisting of $\mathrm{GnRH}$ non-entrapped with ultra-centrifugation at (7.000 G) (12.000 rpm), 10으 for 10 minutes. The amount of free $\mathrm{GnRH}$ hormone in supernatant was measured by spectrophotometry UV at $\lambda=260 \mathrm{~nm}$ (Katas et al., 2013). Entrapment efficiency (EE\%) of GnRH in Chitosan was calculated according to the following formula:

$\mathrm{EE} \%=(\mathrm{GnRH}$ amount - free $\mathrm{GnRH}$ in supernatant $\mathrm{x}$ 100) / Total amount of GnRH

\section{Blood Sampling and Hormonal Assay}

Blood samples were obtained on days -6, -3, 0, 3, $6,7,9$, and 12. Day 0 was the day of first GnRH agonist injection. The obtained blood samples were centrifuged at $1500 \mathrm{G}$ for $15 \mathrm{~min}$ and the harvested serum samples were stored at $-20^{\circ} \mathrm{C}$ until analysis of progesterone, es- tradiol, and insulin. Blood samples were pooled on days 7 and 9 for estradiol detections and on days 9 and 12 for progesterone detections.

\section{Serum Progesterone Assay}

Serum progesterone concentrations were determined using a direct ELISA technique Human, PROG, ELIZA, GmBH, Germany). The kit has a sensitivity of $0.06 \mathrm{ng} / \mathrm{mL}$ with inter- and intra-run precision coefficients of variation of $4.5 \%$ and $2.6 \%$, respectively.

\section{Serum Estradiol Assay}

Serum estradiol concentrations were determined using a direct ELISA technique (Estradiol ELISA Kit ABIN6574085). The kit has a sensitivity of $0.75 \mathrm{pg} / \mathrm{mL}$. The intra-assay and inter-assay coefficient of variation was $<8$ and $<10 \%$, respectively.

\section{Serum Insulin Assay}

Serum insulin concentrations were determined using an Immunoradiometric kit (Insulin (e) IMRA kit; IMMUNOTECH, s.r.o Radiova 1-10227 praque- Czech Republic). The inter-assay and intra-assay coefficients of variations were $8.3 \%$ and $5.6 \%$, respectively. The average sensitivity was $4.55 \mathrm{ng} / \mathrm{mL}$.

\section{Follicular Dynamics}

Transrectal scanning of the ovaries was carried out on days $-3,0,3,6$, and 9. Real time B-mode scanner (Ultrascan model DP-30VET, Shanghai International Holding Group Gmbh, Europe, Hamburg, Germany, equipped with 100-240 v, 50/60 multi frequency; 5e10 MHZ, linear probe) was used to track changes in the diameter of the largest follicle. The ultrasound scanning
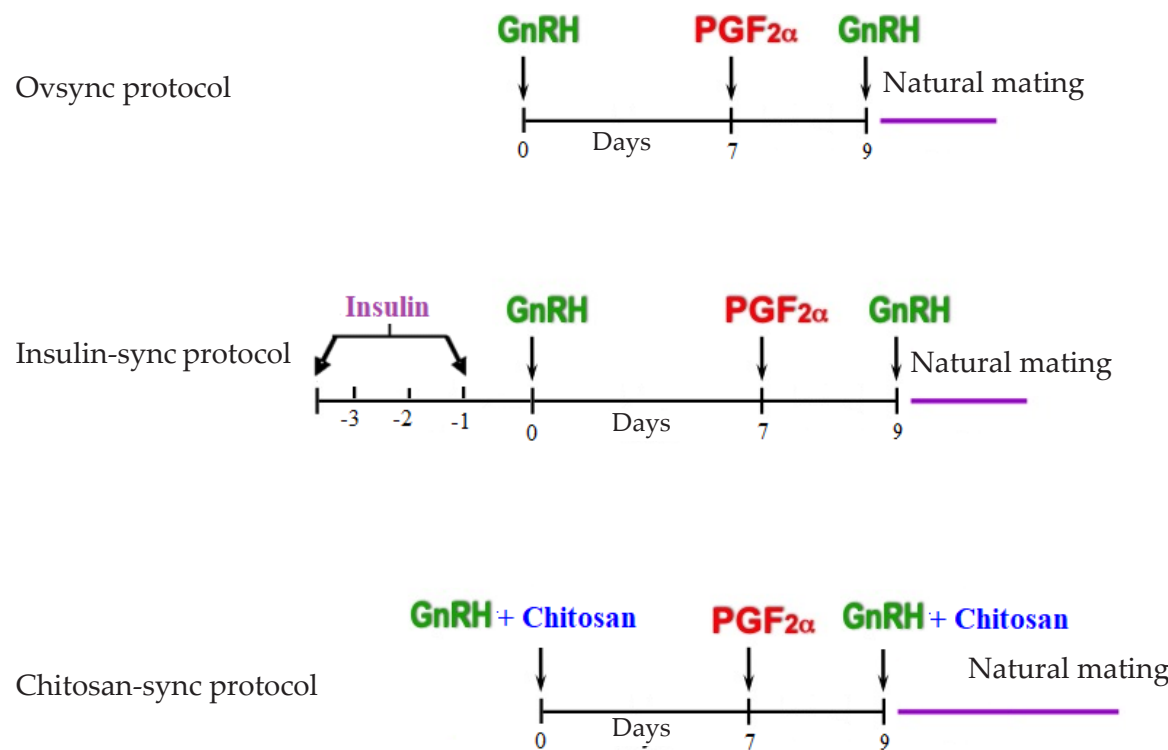

Figure 1. Description of protocols used for treatment of buffaloes suffering from ovarian inactivity during low breeding season 
was continued on 3 days intervals after treatment to measure the development and size of pre-ovulatory follicles and detect the occurrence of estrous.

\section{Reproductive Management}

Herdsman watched the experimental buffaloes two times per day (at $6 \mathrm{AM}$ and $6 \mathrm{PM}$ ) for at least one hour each time to observe estrous signs, especially when the female buffaloes accepted the teaser male. All females came into estrous were recorded so that the estrous induction rate (EIR) also was determined. Different parameters were used to consider female buffaloes succeed to come into estrouses such as the occurrence of estrous signs, acceptance of female to teaser male, and changes in serum progesterone concentrations for each group. Natural matting is the method that was used for insemination of buffalo cows. Scanning of the uterus with the ultrasound device was done on day 45 post mating for checking the occurrence of pregnancy. Conception rates were also detected.

\section{Statistical Analysis}

The data were analyzed by the mixed model ANOVA and general linear model using program of SPSS version 16. The Chi-square test was used to compare conception rates between the groups.

\section{RESULTS}

\section{Onset of Estrous}

The onset of estrous in experimental buffaloes in G1 and G3 started on day 7 and day 10 (after injection of $\mathrm{PGF}_{2 \alpha}$ ), while in $\mathrm{G} 2$, the onset of estrous occurred on the first day after the first injection of GnRH (before administration of $\mathrm{PGF}_{2 \alpha}$ ).

\section{Estrous Induction Rates (EIR)}

The addition of chitosan to GnRH analog and its administration in acyclic buffaloes made them better responded to GnRH treatment. EIR significantly increased in experimental buffaloes in G3 when compared with those in G1 and G2 (p<0.05) (Table 1).

Administration of insulin in anestrous buffaloes for 3 days prior to $\mathrm{GnRH}$ administration lead to the good responses of the experimental buffaloes to $\mathrm{GnRH}$ treatment. EIR significantly increased in experimental buffaloes in G2 (Table 1) compared with those in G1 ( $<<0.05)$.

\section{Conception Rates}

Conception rate was higher $(\mathrm{p}<0.05)$ in experimental buffaloes in G3 compared to those in G1 and G2. In experimental buffaloes in G3, the conception rate was $76.9 \%$ while in G1 and G2, conception rates decreased to the level of $50 \%$ in each group (Table 1 ). In experimental buffaloes in G1, the pregnancy occurred from the second estrous after treatment (first spontaneous) while in experimental buffaloes in G2 and G3, more than 50\% of pregnancy occurred from the first estrous after treatment (induced), and the rest occurred from the second estrous after treatment (first spontaneous).

\section{Size of the Largest Follicle}

The ultrasound examination revealed that there were no significant differences in the size of the largest follicle between the groups of experimental buffaloes on day -3 (i.e., immediately before the first injection of insulin in G2). Injection of insulin caused a significant $(p<0.05)$ increase in the diameter of the largest follicle in G2 compared to G1 and G3 (Table 2). In experimental buffaloes in G3, the size of the largest follicle increased after the injection of $\mathrm{GnRH}$ agonist plus chitosan on

Table 1. Estrous induction rate (EIR) and conception rate of basic Ovsync (G1), insulin-sync (G2) and chitosan-sync (G3) buffaloes treated groups

\begin{tabular}{|c|c|c|c|c|c|c|c|}
\hline \multirow[b]{2}{*}{ Groups } & \multicolumn{3}{|c|}{ Estrus induction rate (frequency) } & \multirow[b]{2}{*}{ Total } & \multicolumn{2}{|c|}{ Conception rate (frequency) } & \multirow[b]{2}{*}{ Total } \\
\hline & Day 1-6 & Day 7-9 & Day 10-12 & & $\begin{array}{l}\text { Induced } \\
\text { estrous }\end{array}$ & $\begin{array}{l}\text { First spontaneous } \\
\text { estrous }\end{array}$ & \\
\hline $\mathrm{G} 1(\mathrm{~N}=45)$ & $0 / 45$ & $5 / 45$ & $7 / 40$ & $12 / 45(26.6 \%)$ & $2 / 12$ & $4 / 10$ & $6 / 12(50 \%)$ \\
\hline $\mathrm{G} 2(\mathrm{~N}=45)$ & $22 / 45$ & $8 / 23$ & 0 & $30 / 45(66.6 \%)$ & $10 / 30$ & $5 / 20$ & $15 / 30(50 \%)$ \\
\hline $\mathrm{G} 3(\mathrm{~N}=45)$ & $0 / 45$ & $9 / 45$ & $30 / 36$ & $39 / 45(86.6 \%)$ & $17 / 39$ & $13 / 22$ & $30 / 39(76.9 \%)$ \\
\hline
\end{tabular}

Table 2. Diameter of the largest follicle (mm) in basic Ovsync (G1), insulin-sync (G2), and chitosan-sync (G3) buffaloes treated groups

\begin{tabular}{|c|c|c|c|c|c|}
\hline \multirow{2}{*}{ Groups } & \multicolumn{2}{|c|}{ Before treatment } & \multicolumn{3}{|c|}{ After treatment } \\
\hline & Day -3 & Day 0 & Day 3 & Day 6 & Day 9 \\
\hline $\mathrm{G} 1(\mathrm{~N}=45)$ & $6.41 \pm 0.22^{\mathrm{aA}}$ & $6.66 \pm 0.22^{\mathrm{aA}}$ & $6.99 \pm 0.22^{\mathrm{aA}}$ & $7.17 \pm 0.07^{\mathrm{aA}}$ & $8.11 \pm 0.12^{\mathrm{bA}}$ \\
\hline $\mathrm{G} 2(\mathrm{~N}=45)$ & $6.47 \pm 0.21^{\mathrm{aA}}$ & $11.17 \pm 0.21^{\mathrm{bB}}$ & $12.33 \pm 0.21^{\mathrm{bc}}$ & $12.63 \pm 0.51^{\mathrm{bC}}$ & $10.10 \pm 0.42^{c \mathrm{C}}$ \\
\hline $\mathrm{G} 3(\mathrm{~N}=45)$ & $6.49 \pm 0.37^{\mathrm{aA}}$ & $6.69 \pm 0.37^{\mathrm{aA}}$ & $8.98 \pm 0.37^{\mathrm{bB}}$ & $10.62 \pm 0.02^{\mathrm{bB}}$ & $12.69 \pm 0.25^{\mathrm{cB}}$ \\
\hline
\end{tabular}

Note: Means \pm SE. Lowercase letters are used for the comparison between values in the same row (within the groups). Uppercase letters are used for comparison between values in the same column (among groups) $(\mathrm{p}<0.05)$. Day -3 ; was the day at which the diameter of the largest follicle was measured in G1 and G3, and immediately before the injection of insulin in G2. Day 0 is the day at which the diameter of the largest follicle was measured in G1 and G3, and after 3 days of insulin injection (Days -3, -2 and -1) in G2 and before gonadotrophin-releasing hormone agonist injection in all groups. 
days three and six post injection and reached its largest size on day nine.

\section{Serum Progesterone Level}

Serum progesterone concentrations were lower before treatment, ensuring acyclicity. In contrast, the progesterone concentrations increased $(p<0.05)$ after treatment indicating the resumption of ovarian activity (Table 3).

\section{Serum Estradiol Level}

Serum estradiol concentrations were lower before treatment, ensuring acyclicity, in addition to its continued lower after treatment in Ovsync treated buffaloes. In contrast, the estradiol concentrations increased $(\mathrm{p}<0.05)$ after treatment in the other two groups G2 and G3 (Table 4).

\section{Serum Insulin level}

Serum insulin concentrations were lower before and after treatment in G1 and G3. In contrast, serum insulin concentrations increased $(\mathrm{p}<0.05)$ after treatment in G2 (Table 5).

\section{DISCUSSION}

Low pregnancy rates were obtained when Ovsync protocol was used in buffaloes during low breeding season (spring and summer). Therefore, several modifications of this protocol have been done to improve fertility response such as chitosan-sync protocol and insulin-sync protocol. In the present study, the EIR obtained in experimental buffaloes in G1 (26.6\%) are in agreement with the results reported previously for buffaloes treated with GnRH (30\%) (Ghuman et al., 2014).

EIR's low rate in the basic Ovsync group was raised in the high temperature and humidity, which have an adverse effect on the pituitary gland's response to GnRH agonist treatment, subsequentially suppress the feedback mechanism. This explanation is in the same line with Vijayalakshmy et al. (2018) who reported that the increased temperature and humidity resulted in a decreased expression of overt signs of estrous due to aberration in endocrine profile. Heat stress during the summer causes hyper-prolactinemia, suppressing the secretion of gonadotropins, which alters the ovarian steroidogenesis. It also affects folliculogenesis (Vijayalakshmy et al., 2018). Therefore, even if GnRH agonist injection resulted in a short-lived release of $\mathrm{LH}$, a large pre-ovulatory follicle is essential to set up the

Table 3. Serum progesterone concentrations (ng/mL) in basic Ovsync (G1), insulin-sync (G2) and chitosan-sync (G3) buffaloes treated groups

\begin{tabular}{|c|c|c|c|c|c|c|}
\hline \multirow{2}{*}{ Groups } & \multicolumn{3}{|c|}{ Before treatment } & \multicolumn{3}{|c|}{ After treatment } \\
\hline & Day -6 & Day -3 & Day 0 & Day 3 & Day 6 & Day 9-12 \\
\hline $\mathrm{G} 1(\mathrm{~N}=45)$ & $0.14 \pm 0.22^{\mathrm{aA}}$ & $0.15 \pm 0.22^{\mathrm{aA}}$ & $0.21 \pm 0.22^{\mathrm{aA}}$ & $0.42 \pm 0.22^{\mathrm{bA}}$ & $0.60 \pm 0.07^{\mathrm{bA}}$ & $1.16 \pm 0.12^{\mathrm{cA}}$ \\
\hline $\mathrm{G} 2(\mathrm{~N}=45)$ & $0.13 \pm 0.21^{\mathrm{aA}}$ & $0.14 \pm 0.21^{\mathrm{aA}}$ & $0.24 \pm 0.21^{\mathrm{aA}}$ & $1.13 \pm 0.21^{\mathrm{bB}}$ & $2.26 \pm 0.51^{\mathrm{cc}}$ & $1.94 \pm 0.42^{\mathrm{cB}}$ \\
\hline $\mathrm{G} 3(\mathrm{~N}=45)$ & $0.15 \pm 0.37^{\mathrm{aA}}$ & $0.15 \pm 0.37^{\mathrm{aA}}$ & $0.23 \pm 0.37^{\mathrm{aA}}$ & $0.86 \pm 0.37^{\mathrm{bB}}$ & $1.12 \pm 0.02^{\mathrm{cB}}$ & $2.29 \pm 0.25^{\mathrm{cB}}$ \\
\hline
\end{tabular}

Note: Means \pm SE. Lowercase letters are used for the comparison between values in the same row (within the groups). Uppercase letters are used for comparison between values in the same column (among groups) $(\mathrm{p}<0.05)$.

Table 4. Serum estradiol concentrations (pg/mL), in basic Ovsync (G1), insulin-sync (G2) andchitosan-sync (G3) buffaloes treated groups

\begin{tabular}{ccccccc}
\hline \multirow{2}{*}{ Groups } & \multicolumn{2}{c}{ Before treatment } & & \multicolumn{3}{c}{ After treatment } \\
\cline { 2 - 3 } \cline { 6 - 7 } & \multicolumn{1}{c}{ Day -3} & Day 0 & & Day 3 & Day 6 & Day $7-9$ \\
\hline G1 $(\mathrm{N}=45)$ & $1.46 \pm 0.12^{\mathrm{aA}}$ & $1.96 \pm 0.22^{\mathrm{aA}}$ & & $2.12 \pm 0.22^{\mathrm{aA}}$ & $5.67 \pm 0.17^{\mathrm{bA}}$ & $7.18 \pm 0.22^{\mathrm{bA}}$ \\
G2(N=45) & $1.47 \pm 0.21^{\mathrm{aA}}$ & $10.97 \pm 0.21^{\mathrm{bB}}$ & & $15.33 \pm 0.21^{\mathrm{cB}}$ & $23.63 \pm 0.51^{\mathrm{dB}}$ & $22.10 \pm 42^{\mathrm{dB}}$ \\
G3(N=45) & $1.49 \pm 0.27^{\mathrm{aA}}$ & $1.89 \pm 0.32^{\mathrm{aA}}$ & & $15.99 \pm 0.17^{\mathrm{bB}}$ & $19.12 \pm 0.02^{\mathrm{cB}}$ & $21.69 \pm 25^{\mathrm{cB}}$ \\
\hline
\end{tabular}

Note: Means \pm SE. Lowercase letters are used for the comparison between values in the same row (within the groups). Uppercase letters are used for comparison between values in the same column (among groups) $(\mathrm{p}<0.05)$.

Table 5. Serum insulin concentrations ( $\mu \mathrm{IU} / \mathrm{mL})$ in in basic Ovsync (G1), insulin-sync (G2) and chitosan-sync(G3) buffaloes treated groups

\begin{tabular}{ccccc}
\hline \multirow{2}{*}{ Groups } & Before treatment & & After treatment \\
\cline { 2 - 3 } \cline { 5 - 5 } & Day -3 & Day 0 & Day 7 \\
G1(N=45) & 2.12 & 2.22 & 2.66 \\
$\mathrm{G} 2(\mathrm{~N}=45)$ & 2.33 & $12.63^{*}$ & $12.99^{*}$ \\
$\mathrm{G} 3(\mathrm{~N}=45)$ & 3.20 & 3.22 & 3.44 \\
\hline
\end{tabular}

Note: Means \pm SE; ${ }^{*}=\mathrm{p}<0.05$. 
series of events occurring prior to reinitiating cyclicity (G1; Table 2).

In the current study, the increase in EIR was significant in G3 and this may be attributed to overcome the problem of short half-life of GnRH which does not exceed 5-6 hours by addition of chitosan. The short halflife time of GnRH in blood circulation, minify both its biological activity and sustained action. GnRH entrapment in chitosan polymer could increase its bioavailability (Rather et al., 2013). It was reported in a previous study carried out in goat that the used dosage of $\mathrm{GnRH}$ was reduced by $75 \%$ after its conjugation by chitosan-sodium tripolyphosphate (TPP) without the occurrence of any deleterious effect in fertility and prolificacy which indicate that chitosan increases the bioavailability of the hormone (Hashem \& Sallam, 2020).

Meanwhile, in experimental buffaloes in G2, the direct effect of insulin administration improved the largest follicle growth (Table 2), thus preparing a follicle to induce estrous and ovulation after GnRH injection and this may be the cause of the significant increase in EIR. These results agree with previous studies (Gupta et al., 2010, Ramoun et al., 2012) confirm that insulin usage for induction of estrous in animals, either alone or in combination with other drugs becomes more encouraged and practical. Furthermore, insulin enhances the follicular growth in true anestrous buffalo, which is a prerequisite for GnRH to be effective (Ramoun et al., 2012).

In addition, insulin promotes LH production through the positive feedback effect of high levels of estradiol produced by the largest follicles. Butler et al. (2004) showed in previous study carried out in cattle that insulin administration increased estradiol production by the follicles. This is also agreed with our result as estrogen level increased after treatment of experimental buffaloes in G2 (Table 4).

Moreover, an increase in serum estrogen level in response to previous insulin injection for 3 days in G2 is proposed to stimulate the release of LH physiologically in spontaneous estrous (3-4 days of pro-estrous phase) in both amplitude and frequency. Meanwhile, the administration of GnRH in G1 animals may only lead to a short-lived release of LH (5-6 h, half-life period of LH).

It has been reported that the ovulation of the DF in buffaloes occurs when its diameter is around $5-8 \mathrm{~mm}$ and heat stress reduces the degree of dominance of the selected follicles. This result appears obviously in this study since the largest follicle of experimental buffaloes in G1 and G3 did not exceed $7 \mathrm{~mm}$ in diameter before GnRH agonist injection. Further addition of chitosan to $\mathrm{GnRH}$ enhances the rate of dominant follicle growth as occurs in experimental buffaloes in G3. In experimental buffaloes in G2, insulin injection for 3 days caused a rapid growth of the dominant follicle (Table 2); and this result is similar to those reported by previous studies (Ramoun et al., 2012, Gupta et al., 2010). These results were also in accordance with results previously showed that the diameter of follicles was 4.2 to $13.0 \mathrm{~mm}$ when GnRH agonist was used for induction of ovulation (Campanile et al., 2007, Campanile et al., 2008).

The significant decrease in the diameter of the largest follicle in G1 may be attributed to treatment by GnRH alone as GnRH gives a significant lesser response in inducing follicular growth and development. Therefore it needs multiple and sequential doses to obtain an optimum effect.

In contrast, in experimental buffaloes in G3, the addition of chitosan to $\mathrm{GnRH}$ agonist leads to the increase in the diameter of the largest follicle as it increases the action of GnRH. The increase in the size of the largest follicle in G3 indicates that chitosan provides sustained and controlled release of the $\mathrm{GnRH}$ hormone and gives evidence about chitosan resistance against enzymatic degradation.

These results are in agreement with the study carried out in fish and showed that injection of half the dose of GnRH conjugated with chitosan resulted in an increased and sustained surge of steroid hormones, especially gonadotropins (FSH and LH), which leads to an increase in follicle maturation and subsequent ovulation, leading to a high reproductive output in the form of total and fertilized eggs (Rather et al., 2013). High drug loading and prolonged drug release are the advantages of using chitosan for delivery of biomolecules (Bhattarai et al., 2006). This result was obvious, especially with the limited half-life of GnRH analogs (5-6 hours), which represents the major side effect of GnRH. Therefore, its usage alone in treatment of acyclic buffaloes is not efficient as it will be variant depending on the size and stage of ovarian follicles at the time of treatment. Therefore, it is concluded that hormone content packed or attached to the biodegradable polymer can be used as a potential hormone carrier by its capability to improve hormone stability and protected it from rapid degradation during hormone transportation and controlling the release of bioactive agents (Rather et al., 2013). Therefore, chitosan is considered to be a safe biomedical material for clinical applications due to its excellent biocompatibility and biodegradability (Saranya et al., 2011). Furthermore, successful GnRH entrapment with chitosan leads to an application of this combination in serious biological processes such as gene delivery. In vitro, GnRH modified by chitosan was successfully developed and tested for delivery of a transgene of interest to spermatogonia cells (Boonthum et al., 2018).

Insulin has receptors present in the ovary. Therefore, insulin has a stimulatory effect on follicular growth. This explains the reasons for the increase in the diameter of the largest follicle in experimental buffaloes in G2 after treatment with insulin (Ramoun et al., 2012). In addition, increasing serum concentration of IGF-1 which stimulates proliferation and steroidogenic activity of granulosa cells, leads to an increase the stimulatory effect of insulin on follicular growth. Therefore, insulin leads to increased estradiol production directly by its own influence on the ovarian follicle (Butler et al., 2004) or indirectly through the increasing sensitivity of FSH's follicle.

Our results came in consonance with Gong et al. (2002), who announced that the maturation of the DF was improved after increasing the insulin and subsequently, the chance of this follicle for ovulation also increased. In addition, these results were in line with previous studies in cows and buffaloes as was reported 
by Ramoun et al. (2012) that administration of insulin increased follicles size. The same result was reported by Butler et al. (2004), who discovered that in dairy cows, the diameter of the largest follicle was significantly increased after exogenous administration of insulin in insulin-treated group compared to the control one.

Breeding season influences conception rate (CR). Buffaloes receiving treatment during breeding season (autumn and winter) exhibited a significant increase in $\mathrm{CR}$ than others in non-breeding season. In experimental buffaloes in G1, conception occurred but was very low (4/15) (27\%). This result is similar to previous results demonstrated that the CR was quite variable: 21.4\% (Karuppanasamy et al., 2017); 30\% (Ghuman et al., 2014); and 20\% (Phogat et al., 2018) when the Ovsync protocol was applied in buffaloes during the unfavorable reproductive season (seasonal anestrous). Khammas \& Ali (2013) also found that pregnancy occurrence was the lowest in GnRH treated group and attributed that to the short half-life of GnRH, so the injection of multiple and sequential doses of $\mathrm{GnRH}$ was recommended to obtain an optimum effect.

In the present study, the achievement of conception in Ovsync group showed that the administration of $\mathrm{GnRH}$ alone might decrease the deleterious influence of high temperature on the follicles of buffaloes respond to treatment. In this case, the heat stressed follicle is replaced with healthy ones through one of two ways, either through ovulation of the dominant follicle or luteinization of smaller ones present at the time of GnRH agonist injection (Wolfenson et al., 1994). This may explain why almost half number of the experimental buffaloes in G1 conceived at the first spontaneous estrous and the other half at the induced estrous. However, GnRH gave a significantly lesser response $(p<0.05)$ to induce follicular growth and development. Since GnRH's half-life is short and needs multiple and sequential doses to obtain an optimum effect (Pierson et al., 2003), it has also been proved by several workers that its effect is restricted mainly in inducing ovulation. This may explain the increase in conception rate in experimental buffaloes in G3 which has chitosan added to GnRH to increase its half-life and increase its efficacy. Rather et al. (2013) reported that the usage of the half-dose rate of GnRH conjugated with chitosan against full dose of non-conjugated $\mathrm{GnRH}$ for testing reproductive efficacy in the female fish, resulted in a higher fertilization rate in case of chitosan conjugated GnRH.

In the current study, measurement of the P4 concentrations gives an accurate indication for the CL from different aspects such as its presence or absence, as well as its size and activity. Previous studies were carried out in buffaloes either in skim milk or plasma (Jazayeri et al., 2010) were in agreement with the present study as they showed the same levels of $\mathrm{P} 4$ recorded here in buffaloes.

In all groups, the progesterone levels were not significantly different until the third day of treatment. Serum progesterone values increased slightly in G1 on days 3 and 6, but the increase was high enough in G3 on the same days. These results revealed that the $\mathrm{CL}$ was more functional in G3 compared to that in G1, and this gives an indication that the addition of chitosan to the GnRH plays a role in making the CL become more active and subsequently provide a significant improvement in conception rate in the experimental buffaloes in G3 compared to those in G1.

Several previous studies differ in the important factors which play a role in the improvement of conception rate. One of these studies said that the most important factor which should be in consideration for the improvement of the conception rates is the presence of high P4 levels at the time of $\mathrm{PGF}_{2 \alpha}$ administration during protocols of treatment for subsequent inseminations (De Rensis et al., 2005). In contrast, one statement was opposite to this mind as it reported that there was no effect noticed on the pregnancy rate from providing P4 on the day of $\mathrm{PGF}_{2 \alpha}$ injection. Another factor was also suggested in the previous study, and this depends on the presence of a large follicle at the beginning of the Ovsync protocol, which will help not only in achieving high conception rates but also in achieving successful synchronization of ovulation (De Rensis et al., 2005). It was also stated that induction of follicular growth in buffaloes previously until it reached to the mature size for ovulation required more exogenous hormone treatments other than GnRH, which may be another factor. The addition of chitosan to GnRH avoids more doses of GnRH required for follicular growth, ovulation, and corpus luteum formation.

In the present study, insulin level was the highest in G2 compared with the other groups and these results came in accordance with the results reported by Abdolghafour \& Saghir (2014), who noticed the presence of an increase in the serum insulin levels in insulin-sync compared with Ovsync group. Heat stressed follicles are influenced by insulin injection since insulin greatly affects its development, maturation, and steroidogenic capacity. In addition, insulin prepares these follicles to ovulate in response to $\mathrm{GnRH}$ agonist injection (Ramoun et al., 2012; Gupta et al., 2010). Therefore, ovulation of these follicles was followed by the formation of well-functional corpora lutea. The same result has occurred in G2 that administration of insulin in addition to GnRH agonist stimulated ovulation and formation of well-functional corpora lutea and this was evidenced by the presence of higher progesterone concentration in G2 compared to G1. These results were also confirmed by another study, which revealed that the conception rate was increased after feeding the animals on a ration leads to the increased level of insulin during post-partum periods (Gong et al., 2002). This effect of insulin may explain why about $60 \%$ of the experimental buffaloes in G2 get pregnant from the first estrous compared to those in G1 and G3.

\section{CONCLUSION}

The addition of chitosan to GnRH increases its efficacy, hastens the growth of ovarian follicles and improves hormonal insufficiency, which results in the increased estrous induction rate and conception rate. Therefore, modified Ovsync protocol with chitosan can be used in treatment of great infertility problems of the summer stressed anestrous buffaloes. However, further 
researches should be done in the future in this field of research to study if this protocol will make the estrous cycle continue to become regular.

\section{CONFLICT OF INTEREST}

The authors have no conflict of interest to declare.

\section{ACKNOWLEDGEMENT}

The authors thank all the workers in the private farm in Qena province.

\section{REFERENCES}

Abdolghafour, B. \& A. Saghir. 2014. Buffalo: a potential animal for quality meat production-a review. Livestock Research International 2: 19-29.

Azawi, O. I., M. D. Ali, O. S. Ahmed, A. S. Al-Hadad, M. S. abeh Jamil, \& A. S. A. Hussien. 2012. Treatment of anestrous in Iraqi buffaloes using ovsynch alone or in combination with CIDR. J. Adv. Vet. Res. 2: 68-72.

Bhattarai, N., H. R. Rama, S.-H. Chou, \& M. Zhang. 2006. Chitosan and lactic acid-grafted chitosan nanoparticles as carriers for prolonged drug delivery. Int. J. Nanomedicine. 1: 181. https://doi.org/10.2147/nano.2006.1.2.181

Boonthum, C., K. Namdee, M. Khongkow, S. Temisak, K. Chatdarong, W. Sajomsang, S. Ponglowhapan, \& T. Yata. 2018. Gonadotropin-releasing hormone-modified chitosan as a safe and efficient gene delivery vector for spermatogonia cells. Reprod. Domest. Anim. 53: 23-28. https://doi. org/10.1111/rda.13346

Butler, S. T., S. H. Pelton, \& W. R. Butler. 2004. Insulin increases $17 \beta$-estradiol production by the dominant follicle of the first postpartum follicle wave in dairy cows. Reproduction 127: 537-545. https://doi.org/10.1530/rep.1.00079

Campanile, G., R. Di Palo, G. Neglia, D. Vecchio, B. Gasparrini, A. Prandi, G. Galiero, \& M. D'occhio. 2007. Corpus luteum function and embryonic mortality in buffaloes treated with a GnRH agonist, hCG and progesterone. Theriogenology 67: 1393-1398. https://doi.org/10.1016/j. theriogenology.2007.03.001

Campanile, G., D. Vecchio, G. Neglia, R. Di Palo, A. Prandi, \& M. D'occhio. 2008. Progesterone and pregnancy status of buffaloes treated with a GnRH agonist. Livest. Sci. 115: 242-248. https://doi.org/10.1016/j.livsci.2007.08.001

Das, K., J. Singh, G. Singh, R. Upadhyay, R. Malik, \& P. Oberoi. 2014. Heat stress alleviation in lactating buffaloes: Effect on physiological response, metabolic hormone, milk production and composition. Indian J. Anim. Sci. 84: 275-80.

Dash, S. 2013. Genetic Evaluation of Fertility Traits in Relation to Heat Stress in Murrah Buffaloes. NDRI, Karnal.

Dash, S., A. Chakravarty, V. Sah, V. Jamuna, R. Behera, R., N. Kashyap, \& B. Deshmukh. 2015. Influence of temperature and humidity on pregnancy rate of Murrah buffaloes under subtropical climate. Asian-Australas. J. Anim. Sci. 28: 943. https://doi.org/10.5713/ajas.14.0825

De Rensis, F., G. Ronci, P. Guarneri, B. X. Nguyen, G. Presicce, G. Huszenicza, \& R. Scaramuzzi. 2005. Conception rate after fixed time insemination following ovsynch protocol with and without progesterone supplementation in cyclic and non-cyclic Mediterranean Italian buffaloes (Bubalus bubalis). Theriogenology 63: 1824-1831. https:// doi.org/10.1016/j.theriogenology.2004.07.024

De Rensis, F. \& R. J. Scaramuzzi. 2003. Heat stress and seasonal effects on reproduction in the dairy cow, a review.
Theriogenology 60: 1139-1151. https://doi.org/10.1016/ S0093-691X(03)00126-2

Domínguez-Delgado, C. L., I. M. Rodríguez-Cruz, E. FuentesPrado, J. J. Escobar-Chávez, G. Vidal-Romero, L. García-González, \& R. I. Puente-Lee. 2014. Drug Carrier Systems Using Chitosan for Non Parenteral Routes. In Pharmacology and Therapeutics. IntechOpen. https://doi. org/10.5772/57235

Ghuman, S., M. Honparkhe, \& J. Singh. 2014. Comparison of ovsynch and progesterone-based protocol for induction of synchronized ovulation and conception rate in subestrous buffalo during low-breeding season. Iran. J. Vet. Res. 15: 375.

Ghuman, S., M. Honparkhe, J. Singh, D. Dhami, A. Kumar, G. Nazir, \& C. Ahuja. 2012. Fertility response using three estrus synchronization regimens in lactating anestrous buffaloes. Indian J. Anim. Sci. 82: 162.

Gong, J., W. Lee, P. Garnsworthy, \& R. Webb. 2002. Effect of dietary-induced increases in circulating insulin concentrations during the early postpartum period on reproductive function in dairy cows. Reproduction 123: 419-427. https:// doi.org/10.1530/rep.0.1230419

Gupta, V., Thakur, M., Agrawal, R., Quadri, M. \& Shukla, S. 2010. Effect of pretreatment with insulin on ovarian and fertility response in true anestrous buffaloes to gonadotrophin-releasing hormone. Buffalo Bull. 29:172-179.

Gupta, K., S. Shukla, P. Inwati, \& O. Shrivastava. 2015. Fertility response in postpartum anoestrus buffaloes (Bubalus bubalis) using modified Ovsynch based timed insemination protocols. Vet. World 8: 316. https://doi.org/10.14202/ vetworld.2015.316-319

Hashem, N. \& S. Sallam. 2020. Reproductive performance of goats treated with free gonadorelin or nanoconjugated gonadorelin at estrus. Domest. Anim. Endocrinol. 71:106390. https://doi.org/10.1016/j.domaniend.2019.106390

Jazayeri, S. P., H. Kohram, \& R. Salehi. 2010. Hormonal responses to $\mathrm{GnRH}$ injection given at different stages of the estrous cycle in water buffaloes. Afr. J. Biotechnol. 9:2169-2172.

Karuppanasamy, K., R. Sharma, S. Phulia, A. Jerome, K. Kavya, K., S. Ghuman, H. Kumar, I. Singh, \& N. Krishnaswamy. 2017. Ovulatory and fertility response using modified heatsynch and ovsynch protocols in the anovular Murrah buffalo (Bubalus bubalis). Theriogenology 95:83-88. https:// doi.org/10.1016/j.theriogenology.2017.02.022

Katas, H., M. A. G. Raja, \& K. L. Lam. 2013. Development of chitosan nanoparticles as a stable drug delivery system for protein/siRNA. Int. J. Biomater. 2013:146320. https://doi. org/10.1155/2013/146320

Khammas, D. \& N. Ali. 2013. Treatment of inactive ovaries in cows and buffalos heifers using a variety of hormones. AL-Qadisiyah Journal of Veterinary Medicine Sciences 12:60-65.

Khan, F., S. Prasad, \& H. Gupta. 2013. Effect of heat stress on pregnancy rates of crossbred dairy cattle in Terai region of Uttarakhand, India. Asian Pacific Journal of Reproduction 2:277-279. https://doi.org/10.1016/S2305-0500(13)60162-1

Martínez-Martínez, M., G. Rodríguez-Berna, I. GonzalezAlvarez, M. A. J. S. Hernández, A. Corma, M. Bermejo, V. Merino, \& M. Gonzalez-Alvarez. 2018. Ionic hydrogel based on chitosan cross-linked with 6-phosphogluconic trisodium salt as a drug delivery system. Biomacromolecules 19:1294-1304. https://doi.org/10.1021/acs.biomac.8b00108

Phogat, J. B., A. K. Pandey, A. K. Balhara, S. S. Ghuman, \& P. Gunwant. 2018. Effects of melatonin supplementation prior to Ovsynch protocol on ovarian activity and conception rates in anestrous Murrah buffalo heifers during out of breeding season. Reprod. Biol. 18:161-168. https://doi. org/10.1016/j.repbio.2018.03.001 
Pierson, J. T., H. Baldassarre, C. L. Keefer, \& B. R. Downey. 2003. Influence of GnRH administration on timing of the LH surge and ovulation in dwarf goats. Theriogenology 60:397-406. https://doi.org/10.1016/S0093-691X(03)00037-2

Ramoun, A., B. Serur, E-S. Fattouh, S. Darweish, \& H. Abou El-Ghait. 2012. Enhancing follicular growth as a prerequisite for $\mathrm{GnRH}$ treatment of true anestrum in buffalo. Anim. Reprod. Sci. 132:29-35. https://doi.org/10.1016/j. anireprosci.2012.03.012

Rather, M. A., R. Sharma, S. Gupta, S. Ferosekhan, V. Ramya, \& S. B. Jadhao. 2013. Chitosan-nanoconjugated hormone nanoparticles for sustained surge of gonadotropins and enhanced reproductive output in female fish. PloS One 8:e57094. https://doi.org/10.1371/journal.pone.0057094

Saranya, N., A. Moorthi, S. Saravanan, M. P. Devi, \& N. Selvamurugan. 2011. Chitosan and its derivatives for gene delivery. Int. J. Biol. Macromol. 48:234-238. https://doi. org/10.1016/j.ijbiomac.2010.11.013

Schüller, L., O. Burfeind, \& W. Heuwieser. 2014. Impact of heat stress on conception rate of dairy cows in the moderate climate considering different temperature-humidity index thresholds, periods relative to breeding, and heat load indices. Theriogenology 81:1050-1057. https://doi. org/10.1016/j.theriogenology.2014.01.029

Solano-Umaña, V., J. R. Vega-Baudrit, \& R. González-Paz. 2015. The new field of the nanomedicine. International Journal of Applied Science and Technology 5:79-88.

Suguna, K., S. Mehrotra, S. Agarwal, M. Hoque, U. Shanker, S. Singh, \& V. Varshney. 2009. Effect of exogenous insulin administration on ovarian function, embryo/ fetal development during pregnancy in goats. Anim. Reprod. Sci. 111:202-213. https://doi.org/10.1016/j. anireprosci.2008.03.021

Vijayalakshmy, K., R. Verma, H. Rahman, H. Prasad Yadav, M. Virmani, D. Kumar, \& V. Choudhiry. 2018. Factors influencing seasonal anestrus in buffaloes and strategies to overcome the summer anestrus in buffaloes. Biol. Rhythm Res. 51:907-914. https://doi.org/10.1080/0929 1016.2018.1558740

Wolfenson, D., M. Kaim, \& M. Rosemberg. 1994. Conception rate of cows supplemented with progesterone post-insemination in the summer. J. Anim. Sci. 72: 280. 